\title{
Big Five Personality Traits and Chronic Low Back Pain: Association with Fear-Avoidance, Anxious and Depressive Moods.
}

\section{Maha E. Ibrahim ${ }^{1}$, Kerstin Weber ${ }^{2}$, Stéphane Genevay ${ }^{3}$ \\ ${ }^{1}$ Rheumatology, Suez Canal University, Ismailia, Egypt. ${ }^{2}$ Medical Direction, University Hospitals of Geneva, Geneva, Switzerland. ${ }^{3}$ Rheumatology, University Hospitals of Geneva, Geneva, Switzerland.}

\section{Introduction}

Emotional and physical dysfunction in chronic back pain patients is mediated by psychological variables rather than by pain severity. Assessing personality traits may help clinicians address the complexity of patients' experiences, and design treatments that target these vulnerabilities.

The Big Five personality model is a version of trait theory which holds that the many ways in which individuals differ in their emotional, interpersonal, experiential, and attitudinal styles can be grouped into five basic factors: Neuroticism, Extraversion, Openness, Conscientiousness and Agreeableness.

This study aimed to identify the distinguishing personality traits of persons seeking treatment for chronic back pain, and to determine associations between those traits and fear avoidance beliefs, depressive, and anxious moods.

\section{Methods}

A total of 102 chronic back pain patients (57\% males) completed the NEO Personality Inventory-Revised, the Tampa Scale for Kinesiophobia (TSK), and the Hospital Anxiety and Depression Scale (HADS).

One Sample t-test was used to compare sample personality means with average population norms. Association between the five personality domains with TSK and HADS scores was assessed using Pearson's correlation. Linear regression was used to estimate associations adjusted for covariates (age, gender, duration of current episode and pain level).

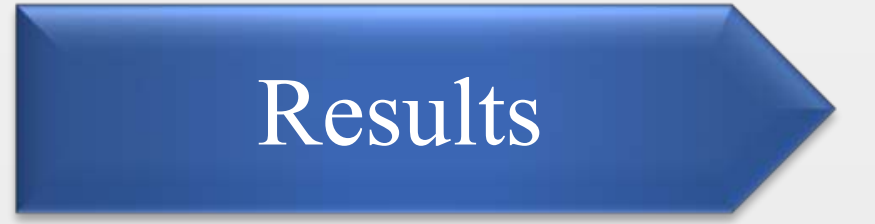

\section{Comparison of Population and Sample mean scores in Personality domains}

\begin{tabular}{|c|c|c|c|}
\hline Domains & $\begin{array}{c}\text { Sample } \\
\text { Mean }\end{array}$ & $\begin{array}{c}\text { Population } \\
\text { Mean }\end{array}$ & $P$ value \\
\hline \multicolumn{4}{|l|}{ Men $(n=59)$} \\
\hline Neuroticism & 88.6 & 86.5 & 0.44 \\
\hline Extraversion & 106.7 & 110.5 & 0.10 \\
\hline Openness & 105.0 & 115.5 & $\mathbf{P}<0.01 * *$ \\
\hline Agreeableness & 120.5 & 117.5 & 0.23 \\
\hline Conscientiousness & 124.0 & 115.5 & $\mathbf{P}<0.01 * *$ \\
\hline \multicolumn{4}{|l|}{ Women $(n=43)$} \\
\hline Neuroticism & 94.6 & 96.5 & 0.64 \\
\hline Extraversion & 104.8 & 110 & 0.10 \\
\hline Openness & 108.7 & 117.5 & $\mathbf{P}<0.01 * *$ \\
\hline Agreeableness & 129.5 & 124 & $P=0.02 *$ \\
\hline Conscientiousness & 124.5 & 116.5 & $\mathbf{P}<0.01 * *$ \\
\hline
\end{tabular}

Association of personality domains with fear avoidance, anxiety and depression $(n=102)$

\begin{tabular}{lcccccc}
\hline \multicolumn{1}{c}{ Domains } & \multicolumn{2}{c}{ TSK } & \multicolumn{2}{c}{$\begin{array}{c}\text { HADS } \\
\text { anxiety }\end{array}$} & \multicolumn{2}{c}{$\begin{array}{c}\text { HADS } \\
\text { depression }\end{array}$} \\
\hline & coef & coef $^{\mathrm{a}}$ & coef & coef $^{\mathrm{a}}$ & coef & coef $^{\mathrm{a}}$ \\
\hline Neuroticism & $0.21^{*}$ & $0.25^{*}$ & $0.44^{* *}$ & $0.49^{* *}$ & $0.35^{* *}$ & $0.38^{* *}$ \\
Extraversion & -0.19 & $-0.23^{*}$ & -0.16 & -0.21 & $-0.25^{*}$ & $-0.28^{* *}$ \\
Openness & -0.14 & -0.13 & -0.04 & -0.04 & $-0.27^{* *}$ & $-0.27^{* *}$ \\
Agreeableness & -0.19 & -0.17 & -0.09 & -0.15 & -0.12 & -0.17 \\
$\begin{array}{l}\text { Conscientious- } \\
\text { ness }\end{array}$ & -0.07 & -0.08 & -0.15 & $-0.21^{*}$ & $-0.20^{*}$ & $-0.21^{*}$ \\
$\begin{array}{l}\text { a Adjusted for age, gender duration of current episode, and pain level. } \\
*<0.05 \\
* *<0.01\end{array}$ & & & & & & \\
\hline
\end{tabular}

\section{Conclusions}

Chronic back pain patients present lower Openness to experience and higher Conscientiousness in comparison to the general population norms Neuroticism, Extraversion, Openness to experience and Conscientiousness significantly correlate with fear avoidance and/or depressive and anxious moods. Clinicians will benefit from assessing patients' personality traits to address protective and risk factors for psychological distress in back pain patients. 